Tropical Journal of Pharmaceutical Research December 2016; 15 (12): 2675-2682

ISSN: $1596-5996$ (print); 1596-9827 (electronic)

(c) Pharmacotherapy Group, Faculty of Pharmacy, University of Benin, Benin City, 300001 Nigeria.

All rights reserved.

Available online at http://www.tjpr.org

Original Research Article

http://dx.doi.org/10.4314/tjpr.v15i12.20

\title{
19F-nuclear magnetic resonance spectroscopy as a tool to investigate host-guest complexation of some antidepressant drugs with natural and modified cyclodextrins
}

\author{
Leila Shafiee Dastjerdi ${ }^{1 *}$ and Mojtaba Shamsipur ${ }^{2}$ \\ ${ }^{1}$ Faculty of Science, Roudehen Branch, Islamic Azad University, Tehran, ${ }^{2}$ Department of Chemistry, Razi University,
} Kermanshah, Iran

*For correspondence: Email: Shafiee_l@yahoo.com; Shafiei@riau.ac.ir; Tel: +98 21 88140116; Fax: +98 2188341159

Received: 10 June 2016

Revised accepted: 12 November 2016

\begin{abstract}
Purpose: ${ }^{19} \mathrm{~F}$-Nuclear magnetic resonance spectroscopy $\left({ }^{19} \mathrm{~F}\right.$-NMR) was used to study host-guest complexation of three fluorine containing antidepressant drugs, viz, fluoxetine hydrochloride, citalopram hydrobromide and fluvoxamine maleate, with various cyclodextrins $(C D)$, including $\alpha$-, $\beta$-cyclodextrin, methylated $\alpha$-cyclodextrin (M- $\alpha-C D)$, diamino derivative of methylated $\alpha$-cyclodextrin, $(D A M-\alpha-C D)$ and tetramino derivative of methylated a-cyclodextrin (TAM- $\alpha-C D)$.

Methods: Using the mole ratio method, a 1:1 stoichiometry was determined for the resulting inclusion complexes. ${ }^{19} \mathrm{~F}$ chemical shifts were used to determine the formation constant of the complexes. Experiments were performed with solutions containing $0.001 \mathrm{M}$ drug and various concentrations of CDs. NMR data were plotted as ${ }^{19} \mathrm{~F}$ chemical shift versus $C D / d r u g$ mole ratio, and fitted using the nonlinear least-squares curve fitting program, KINFIT, to obtain the formation constant of CD-drug complex. Molecular modeling (MM) calculations were used to predict the geometry of the complex of fluvoxamine and $\beta-C D$. Molecular modeling studies were performed in vacuum phase, employing empirical force fields and semi-empirical quantum theory using AM1 Hamiltonian.

Results: Complex formation caused separation of the fluorine peaks that can be assigned to the two enantiomers of fluoxetine hydrochloride. Molecular modeling data suggest that fluvoxamine/ $\beta-C D$ inclusion complexes have a 1:1 stoichiometry and that the CF3-substituted ring of fluvoxamine is embedded in the cavity of $\beta-C D$, indicating a good agreement between molecular modeling calculation and experimental data (NMR data).

Conclusion: One-dimensional 19F-NMR is a fast and convenient method for the determination of complex stoichiometry and complexation constants of natural and modified CDs and fluorinated drugs.
\end{abstract}

Keywords: Antidepressant drugs, Cyclodextrins, Complexation, Inclusion complex, Formation constant, ${ }^{19}$ F-NMR

Tropical Journal of Pharmaceutical Research is indexed by Science Citation Index (SciSearch), Scopus, International Pharmaceutical Abstract, Chemical Abstracts, Embase, Index Copernicus, EBSCO, African Index Medicus, JournalSeek, Journal Citation Reports/Science Edition, Directory of Open Access Journals (DOAJ), African Journal Online, Bioline International, Open-J-Gate and Pharmacy Abstracts

\section{INTRODUCTION}

As a strategy to reduce the drawbacks of many pharmaceutical formulations, polymers, liposomes and cyclodextrins (CDs) have been used as controlled or sustained release systems.
These modified release systems can provide a reduction of drug concentration or decrease in the dose administration per day. The CDs has attracted the attention not only in the pharmaceutical formulations but also in food and biological areas, because of their ability to form 
inclusion compounds (ICs) with guest molecules in solutions or solid-state [1-3]. Indeed, CDs have been used extensively in pharmaceutical formulations as solubilizers to enhance oral bioavailability [4].

Cyclodextrins (CDs) are cyclic oligosaccharides consisting of six ( $\alpha-C D)$, seven $(\beta-C D)$, or eight $(\gamma-C D)$ glucopyranose units in their structure [5]. Due to formation of $\alpha-1,4-$ glycosidic linkage, CDs are doughnut shaped molecules, possessing hollow cavities which can accommodate a variety of guests in aqueous solution and in the crystalline state by non-covalent interactions $[6,7]$. The presence of hydroxyl groups on the exterior surface of CDs make them fairly polar while the interior of the cavity is relatively nonpolar. The slightly hydrophobic character of the inner cavity provides a driving force for hostguest complexation with similarly apolar guest molecules [7].

The prediction of the behavior of guests such as drugs in CD solution is dependent on the complexation constant (also called the stability or formation constant) for the CD-guest complex, and the stoichiometry of complexation. Measurements of complexation induced chemical-shift displacements (up- or downfield) in nuclear magnetic resonance spectroscopy as a function of concentrations (NMR titrations) can be used to determine the complexation constant and changes in chemical shifts resulting from inclusion of the guest molecule in the CD cavity. Compared to other methods of equilibrium determinations, these methods have the advantage of providing several independent signals for the evaluation of stability constants [8].

Fluorine $\left({ }^{19} \mathrm{~F}\right) \quad$ NMR has been used to demonstrate the complexation of natural $\beta-C D$ with perfluorinated ends of telomeric polymers [911] and fluorinated amino acid derivatives [12]. Fluorine as a group is rare in natural compounds, but is a relatively common substitute in drugs. Some drugs have fluorine(s) in their structures, e.g., psychotropic drugs, synthetic steroidal hormones and new quinolone drugs. They are widely used clinically because the introduction of fluorine atom(s) into the drugs improves their pharmaceutical activities or induces new pharmaceutical activities [13]. This method is limited by the fact that a majority of drugs do not contain fluorine, but when it is applicable; 19FNMR should have certain advantages over the more commonly applied proton $\left({ }^{1} \mathrm{H}\right)$ and carbon $\left({ }^{13} \mathrm{C}\right)$ NMR methods. In comparison to ${ }^{1} \mathrm{H}$-NMR, the absolute chemical-shift variation is an order of magnitude larger for ${ }^{19} \mathrm{~F}-\mathrm{NMR}$, and peak broadening, which often makes CD complexation-induced chemical-shift determinations in ${ }^{1} \mathrm{H}$-NMR difficult, is less observed. While the absolute chemical-shift variation may be similar in ${ }^{13} \mathrm{C}$ - and ${ }^{19} \mathrm{~F}$-NMR, the latter method is more sensitive since the natural abundance of the measured isotope is $100 \%$, compared to $1.1 \%$ for ${ }^{13} \mathrm{C}$, allowing less timeconsuming collection of data. Overlapping of CD and guest signals, which is frequently encountered in ${ }^{1} \mathrm{H}$ - and ${ }^{13} \mathrm{C}-\mathrm{NMR}$, is also eliminated. This study was aimed at investigating whether ${ }^{19} \mathrm{~F}-\mathrm{NMR}$ is a suitable method for determination of complex stoichiometry and complexation constants of the natural and modified CDs and fluorinated drugs. The structures of fluorine-containing antidepressant drugs and modified cyclodextrins used in this study are shown in Figure 1.

\section{EXPERIMENTAL}

\section{Materials and reagents}

Analytical grade, high-purity substances were used throughout this study. Racemic fluoxetine (as the hydrochloride salt) was obtained from Recordati, Spain. Citalopram hydrobromide was purchased from Ranboxy, India. Fluvoxamine maleate was obtained from Solvay-Duphar, Netherlands. These drug standards were used without any further purification. Deuterium oxide (> $99.9 \%$ ) was supplied by Merck (Darmstadt, Germany). $\alpha$ - and $\beta$-Cyclodextrins were purchased from Fluka (Buchs, Switzerland). Methylated $\alpha$-cyclodextrin $(M-\alpha-C D)$, tetramino derivative of methylated $\alpha$-cyclodextrin, 6B,6C,6E,6F-tetramino-6B,6C,6E,6F -tetradeoxy $-2 \mathrm{~A}, 2 \mathrm{~B}, 2 \mathrm{C}, 2 \mathrm{D}, 2 \mathrm{E}, 2 \mathrm{~F}, 3 \mathrm{~A}, 3 \mathrm{~B}, 3 \mathrm{C}, 3 \mathrm{D}, 3 \mathrm{E}, 3 \mathrm{~F}, 6 \mathrm{~A}, 6 \mathrm{D}-$ tetradeca-O-methylcyclomaltohe-xaose (TAM- $\alpha$ $\mathrm{CD})$ and diamino derivative of methylated $\alpha$ cyclodextrin,6A,6D-diamino-6A,6D-dideoxy-2A, 2B, 2C, 2D,2E, 2F, 3A, 3B, 3C,3D,3E,3F,6B,6C,6E, 6F-hexadeca-O-methylcyclomalto-hexaose (DAM-a-CD) [14] were a gift of prof. Matt (Laboratoire de Chimie Inorganique et Catalyse, Université de Strasbourg, Strasbourg, France).

\section{Instrumentation}

All ${ }^{19} \mathrm{~F}-\mathrm{NMR}$ spectra were recorded on a BRUKER DRX 500 AVANCE (11.7 T) spectrometer operating at $470.59 \mathrm{MHz}{ }^{19} \mathrm{~F}$ observation frequency, equipped with a dedicated 5-mm QNP probehead and running XWIN-NMR 2.6 software using $500 \mu \mathrm{l}$ of samples.

Trop J Pharm Res, December 2016; 15(12): 2676 


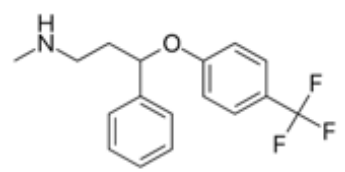

Fluoxetine

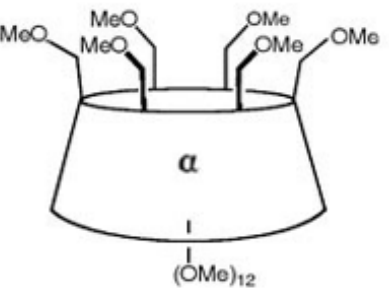

M- $\alpha-$ CD

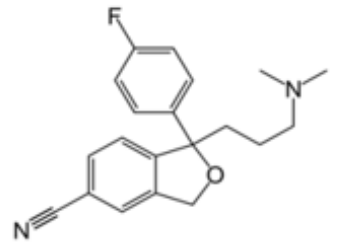

Citalopram

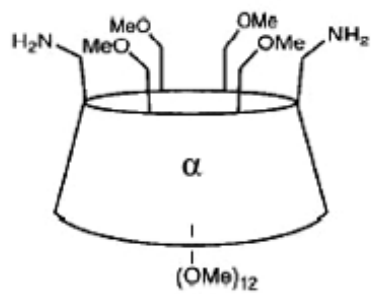

DAM- $a-C D$

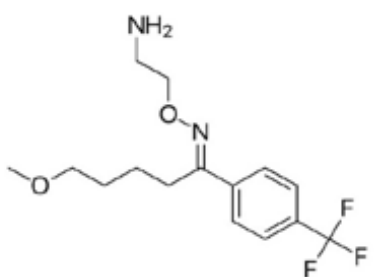

Fluvoxamine

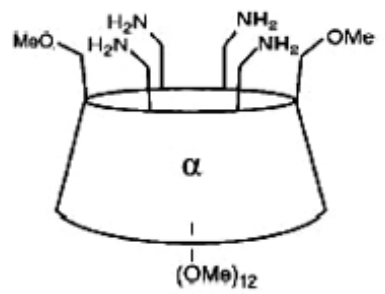

TAM- $a-$ CD

Figure 1: Chemical structures of the fluorine-containing antidepressant drugs and the modified cyclodextrins used in this study

In all experiments, a known amount of $\mathrm{D}_{2} \mathrm{O}(100$ $\mu$ l) was added as an internal field frequency lock. Spectra were recorded at $298 \pm 1 \mathrm{~K}$ and the ${ }^{19} \mathrm{~F}$ NMR chemical shifts were reported relative to trichlorofluoromethane $\left(\mathrm{CFCl}_{3}\right)$ at $\delta_{\mathrm{F}}=0.0 \mathrm{ppm}$. The spectra were generally obtained in 16 to 64 scans, depending on the sample concentration.

\section{Calculations}

NMR data was plotted as the variation of the ${ }^{19} \mathrm{~F}$ chemical shift against $\mathrm{CD} / \mathrm{drug}$ mole ratio and fitted to the following equation using the nonlinear least-squares curve fitting program KINFIT [15] to obtain the formation constant of 1:1 CD-drug complex (Eq.(1)):

$$
\begin{aligned}
& \delta_{\text {obs }}=\left\{\left[K_{f} C_{D} C_{C D}-1\right)+\left(K_{f}^{2} C_{C D}^{2}+K_{f}^{2} C_{D}^{2}\right.\right. \\
& -2 K_{f}^{2} C_{C D} C_{D}+2 K_{f} C_{C D}+2 K_{f}+2 K_{f} C_{D} \\
& \left.\left.+1)^{1 / 2}\right] \frac{\delta_{D}-\delta_{\text {drug }-C D}}{2 K_{f} C_{D}}\right\}+\delta_{\text {drug }-C D}
\end{aligned}
$$

where $\delta_{\text {obs }}$ is the observed chemical shift of the drug, $K_{f}$ is the formation constant for the 1:1 complex, $C_{C D}$ and $C_{D}$ are the analytical concentrations of the cyclodextrin and drug, respectively, and $\delta_{D}$ and $\delta_{\text {drug-CD }}$ are the respective chemical shifts of the free and complexed drug.

\section{RESULTS}

${ }^{19} \mathrm{~F}$ NMR spectra of fluoxetine hydrochloride were obtained in aqueous solution in the absence and presence of increasing amount of different cyclodextrins. Experiments were performed with solutions containing $0.001 \mathrm{M}$ fluoxetine and having different concentrations of CDs ( $\alpha-C D, M-$ $\alpha-C D, D A M-\alpha-C D, T A M-\alpha-C D$ and $\beta-C D)$. All the spectra contained one set of resonances suggesting a fast equilibrium between the free and complexed forms of the drug, on the NMR time scale.

Typically, the changes observed in the successive ${ }^{19} \mathrm{~F}$ NMR spectra of fluoxetine upon addition of M- $\alpha-C D$ and DAM- $\alpha-C D$ is shown in Figure 2. The ${ }^{19} \mathrm{~F}$ chemical shifts of each of the two fluoxetine hydrochloride enantiomers as a function of $C D / f l u o x e t i n e$ mole ratios in the presence of M- $\alpha-C D$, DAM- $\alpha-C D, T A M-\alpha-C D$ and $\beta-C D$ are illustrated in Figure 3. 

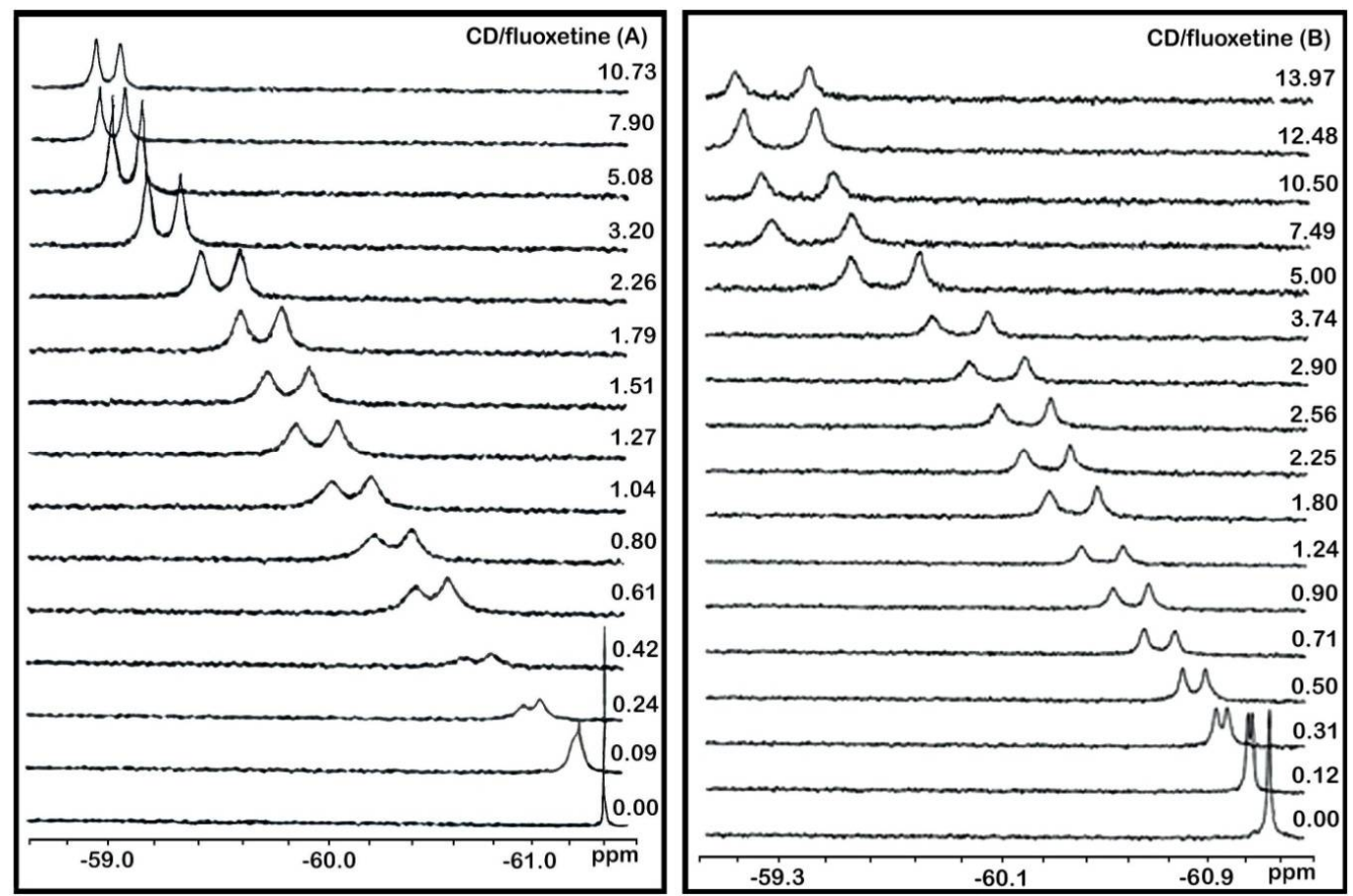

Figure 2: ${ }^{19} \mathrm{~F}-\mathrm{NMR}$ spectra of $0.001 \mathrm{M}$ fluoxetine hydrochloride at various $\mathrm{CD} / \mathrm{fluoxetine}$ mole ratios in the presence of $\mathrm{M}-\alpha-\mathrm{CD}(\mathrm{A})$ and DAM- $\alpha-\mathrm{CD}(\mathrm{B})$

$K_{\mathrm{f}}$ values were obtained from nonlinear fitting the $\delta_{\text {obs }}$ versus $C_{C D}$ data (at constant $C_{D}$ of $0.001 \mathrm{M}$ ) to Eq 1. A sample computer fit of the ${ }^{19} \mathrm{~F}$

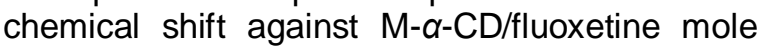
ratio data for the $(R)$-fluoxetine and $(S)$ fluoxetine is shown in Figure 4 and the calculated $\log K_{\mathrm{f}}$ values for each of the fluoxetine enantiomers are given in Table 1. As it can be observed in Figure 4, a good agreement between the experimental and calculated chemical shifts supports the formation of a complex with 1:1 stoichiometry between drug and $C D$.

In the present work, it also investigated the complexation of citalopram hydrobromide and fluvoxamine maleate with $\alpha$-CD, M- $\alpha-C D$, DAM$\alpha-C D$ and $\beta-C D$. Experiments were performed with solutions containing $0.001 \mathrm{M}$ drug and having different concentrations of CDs. The $K_{\mathrm{f}}$ values were evaluated by fitting the chemical shift-mole ratio data to Eq 1 using the KINFIT program for a 1:1 complex model. The resulting $\log K_{\mathrm{f}}$ values are included in Table 1.

The results from the ${ }^{19} \mathrm{~F}$-NMR study show that the fluvoxamine phenyl group with the $-\mathrm{CF}_{3}$ substitution remains outside the $\alpha$-CD cavity, as it does not undergo any significant spectral changes.

In order to gain further insights into the inclusion process, molecular modeling (MM) calculations was used to predict the geometry of the complex of fluvoxamine and $\beta$-CD. Molecular modeling studies were performed in vacuum phase employing the empirical force fields and semiempirical quantum theory using the AM1 Hamiltonian. The initial geometry of fluvoxamine was obtained using a full geometry optimization at the level of B3LYP/6-31 $++G^{* *}$ and the initial geometry of $\beta-C D$ was obtained using a full geometry optimization at the level of AM1 based on the available crystallography data [16]. The initial docked structure of the inclusion complex of fluvoxamine and $\beta-C D$ was obtained using the simulated annealing method, with a rigid geometry and fixed partial charges for the individual molecules. The calculations were performed by HyperChem [17] and Gaussian 98 packages of program [18]. The minimum energy structure of the complex obtained is shown in Figure 5.

\section{DISCUSSION}

In the ${ }^{19} \mathrm{~F}$-NMR spectra, fluoxetine has one strong singlet at $-61.3 \mathrm{ppm}$. Fluoxetine is a racemic mixture and addition of different CDs (except $\alpha-C D$ ) resulted in separation of the enantiomers in the ${ }^{19} \mathrm{~F}$-NMR spectra, with different chemical shifts for either enantiomer. In fact, because of the formation of diastereomeric complexes between the CDs and the fluoxetine enantiomers, a doublet set of more or less shifted signals can be seen for the diastereomers. Thus, the presence of two enantiomers can be demonstrated simply by the 

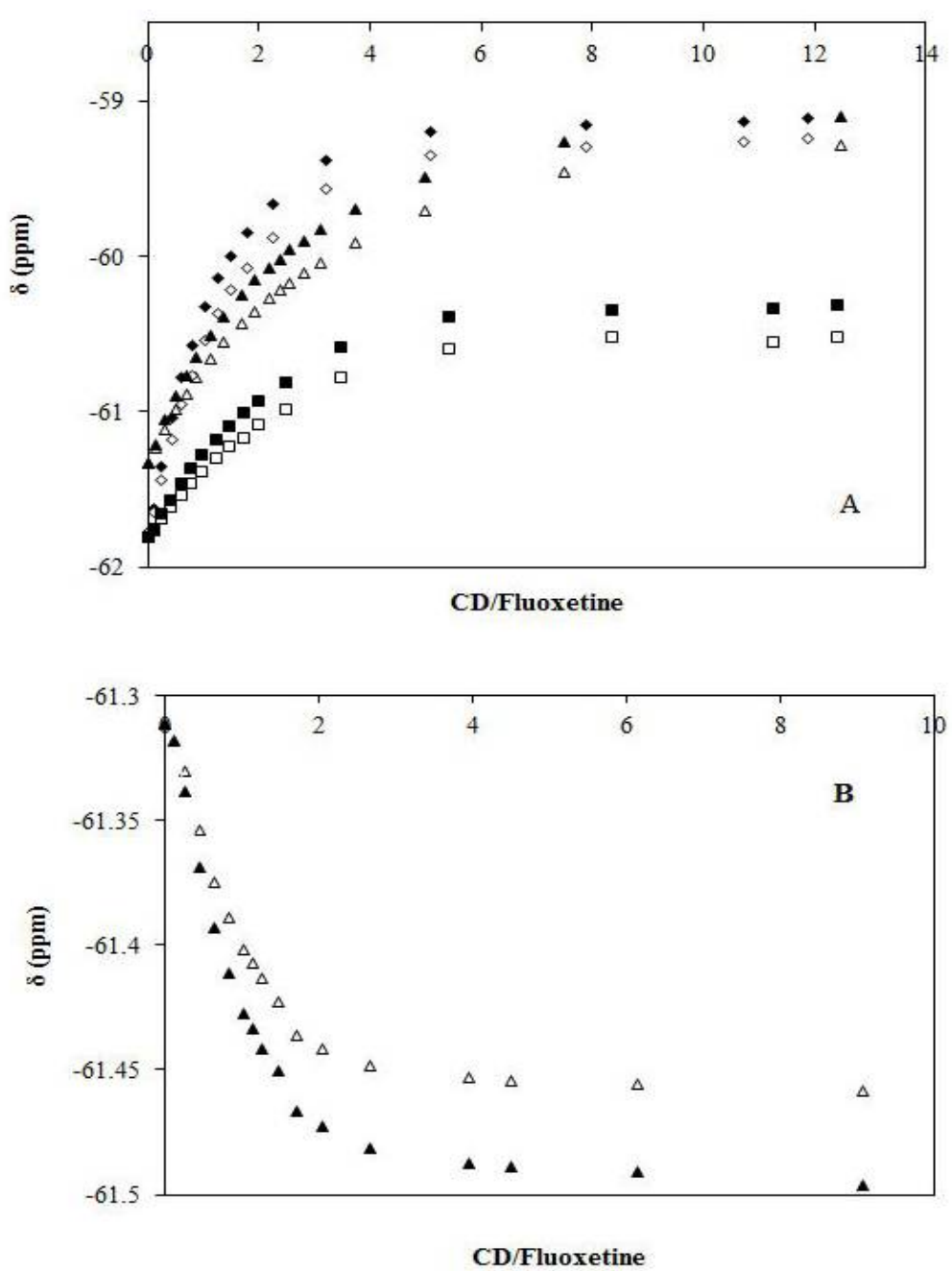

Figure 3: Fluorine-19 chemical shifts of each of the two fluoxetine hydrochloride enantiomers as a function of $\mathrm{CD} /$ fluoxetine mole ratios in the presence of $\mathrm{M}-\alpha-\operatorname{CD}(\bullet, \diamond)$, DAM- $\alpha-\operatorname{CD}(\boldsymbol{\Lambda}, \Delta)$ and TAM- $\alpha-\mathrm{CD}(\boldsymbol{\bullet}, \square)(\mathrm{A})$ and $\beta-\mathrm{CD}$ (B)

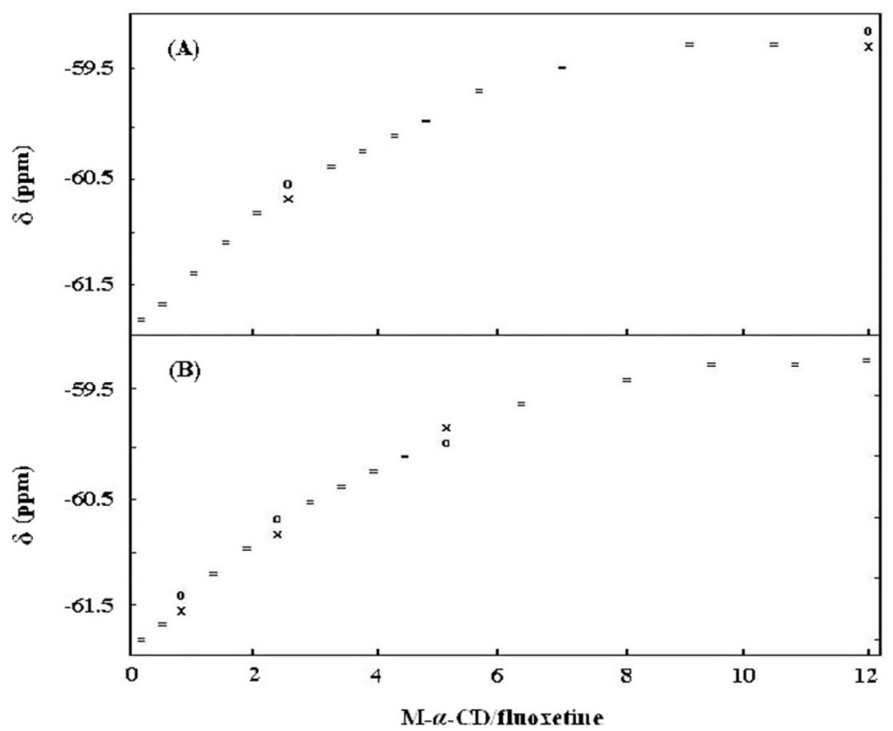

Figure 4: Computer fit of ${ }^{19} \mathrm{~F}$ chemical shift vs. M- $\alpha$-CD/fluoxetine mole ratio for the $(R)$-fluoxetine $(\mathrm{A})$ and $(S)$ fluoxetine $(B):(x)$ experimental point; $(\circ)$ calculated point; $(=)$ experimental and calculated points are the same within the resolution of the plot 
Table 1: Formation constants of 1:1 complexes of fluoxetine, citalopram and fluvoxamine with the natural and modified cyclodextrins

\begin{tabular}{lcccc}
\hline Cyclodextrin & \multicolumn{4}{c}{$\log \boldsymbol{K}_{\mathrm{f}}{ }^{a}$} \\
\cline { 2 - 5 } & $(\boldsymbol{R})-$ Fluoxetine & $(\mathbf{S})-$ Fluoxetine & Citalopram & Fluvoxamine \\
\hline$\alpha-C D^{D}$ & $1.50 \pm 0.08$ & $1.50 \pm 0.08$ & $2.54 \pm 0.07$ & --- \\
M- $\alpha$-CD & $2.90 \pm 0.02$ & $2.85 \pm 0.03$ & $3.31 \pm 0.03$ & $2.82 \pm 0.02$ \\
DAM- $\alpha$-CD & $2.49 \pm 0.07$ & $2.37 \pm 0.02$ & $2.96 \pm 0.03$ & $2.02 \pm 0.06$ \\
TAM- $\alpha$-CD & $2.43 \pm 0.04$ & $2.30 \pm 0.06$ & --- & -- \\
$\beta-C D$ & $3.32 \pm 0.07$ & $3.37 \pm 0.06$ & $2.97 \pm 0.04$ & $3.29 \pm 0.07$ \\
\hline
\end{tabular}

${ }^{a}$ The errors associated with $\log K_{\mathrm{f}}$ values are \pm standard deviation (SD); ${ }^{b} \alpha$-CD failed to resolve the enantiomers of fluoxetine
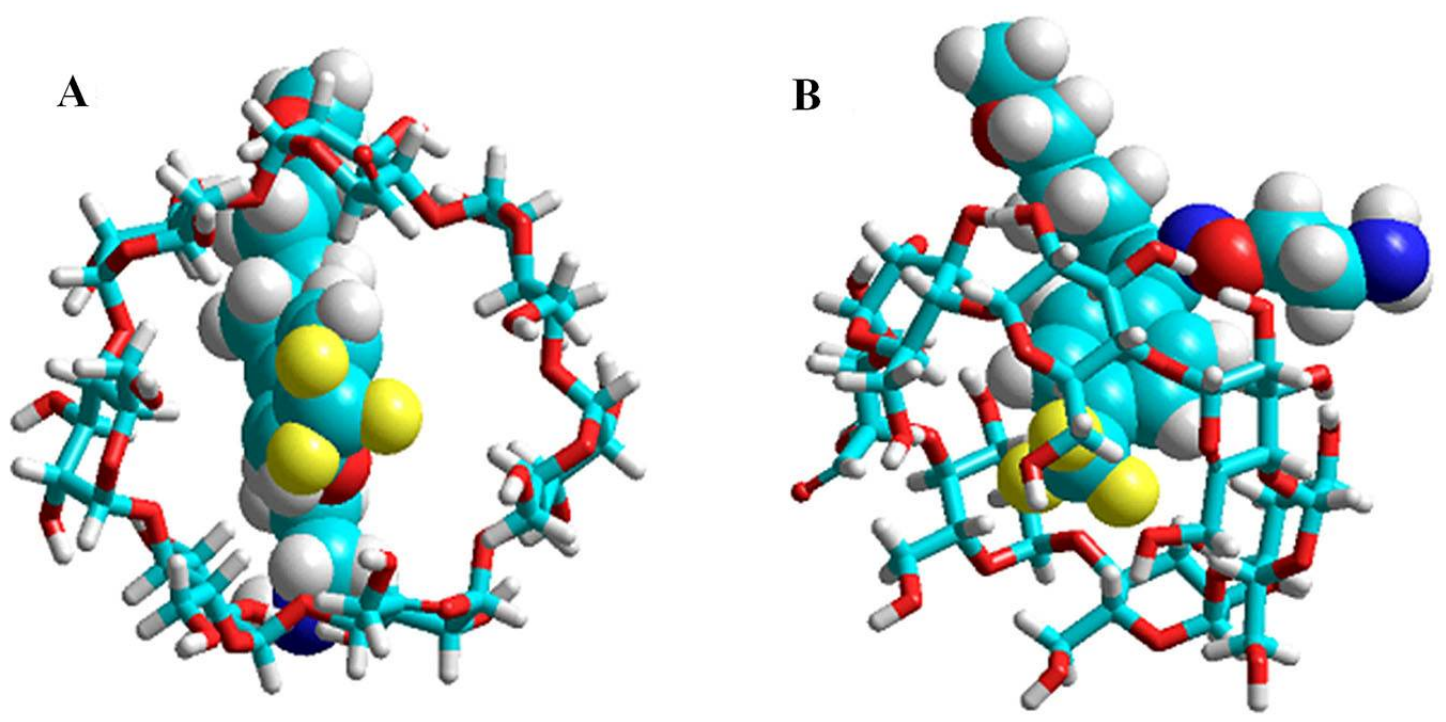

Figure 5: Relative host-guest geometry corresponding to the minimum of the energy of the formation of fluvoxamine/ $\beta-C D$ complex. Top view $(A)$ and side view $(B)$

addition of CD, and equal size of the peaks confirmed that the enantiomers were present in equimolar quantities.

The data given in Table 1 clearly indicate the formation constants are almost the same for both enantiomers of fluoxetine with CDs, showing that the extent of inclusion of the guest into the CD cavity is the similar for two enantiomers. 19FNMR spectroscopy of mixtures of fluoxetine hydrochloride and different CDs revealed the existence of inclusion complexes formed by the penetration of CF3-substituted ring into the CD cavity, in analogy to previously reported findings for complex of fluoxetine with $\beta-C D[3,7]$.

A primary criterion for the inclusion of a guest molecule within the host's cavity is obviously its size and then other factors such as strict fit, van der Waals' interactions, hydrogen bonding and so on $[19,20]$. As can be seen in the Table 1, the $\mathrm{Kf}$ values obtained for the complexes of fluoxetine and fluvoxamine with $\beta-C D$ is somewhat higher than the other cyclodextrins. It is most possibly due to the consonance between the size of $\beta-C D$ cavity and the size of included group inside cavity.

It is interesting to note that, methylated derivatives of $\alpha-C D$ possess stronger ability for the complexation than the parent $\alpha-C D$. This probably reflects the ability of flexible permethylated CDs to better adapt their shape to that of the included guest molecules. Chemical modification [21], notably permethylation, often renders the macrocyclic structure much more flexible as a result of interglucose $O(2) n . . . O(3) n-$ 1 hydrogen bond breaking which can lead to significant shape modification of the torus $[22,23]$. It is pointed out that per-2,3,6-methylated CDs are more water soluble at room temperature than their natural analogues and retain inclusion properties to a certain extent [24]. Furthermore, a comparison between the binding constant values of resulting 1:1 complexes of fluoxetine molecule with modified $\alpha-C D s$ show that the structure of

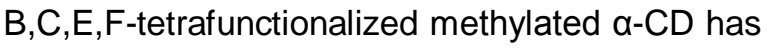
become more rigid than $A, D$-difunctionalized methylated $\alpha-C D$. 
The $\mathrm{Kf}$ values obtained for the complex of citalopram with different CDs (Table 1) reveal the permethylation of cyclodextrins enhance their complex forming ability. As mentioned above, it can be explained by changes in the shape of the cyclodextrin cavity to accommodate the guest molecule.

The molecular modeling data suggest that fluvoxamine/ $\beta-C D$ inclusion complexes have a $1: 1$ stoichiometry and that the CF3-substituted ring of fluvoxamine is embedded in the cavity of $\beta-C D$ (Figure 5). Therefore, the results reported show a good agreement between MM calculation and experimental data (NMR data).

\section{CONCLUSION}

${ }^{19} \mathrm{~F}$-NMR titrations and mole ratio methods are easy to perform and fast. These methods can be used to determine complexation stoichiometry and formation constants between fluorinecontaining drugs and $C D$ derivatives, provided that the fluorine is embedded into the CD cavity when the complex is formed. For convenient use of this method, the drug must have a relatively high intrinsic solubility so that the acquisition time for each sample is within few minutes. This method could be used to measure enantiomeric composition of chiral compounds, since only very small additions of CD cause separation of peaks in the spectra [25].

\section{DECLARATIONS}

\section{Acknowledgement}

The authors are grateful to Prof D Matt, Laboratoire de Chimie Inorganique et Catalyse, Université de Strasbourg of France, for the gift of modified $\alpha-C D, M r ~ H R$ Bijanzadeh at the University of Tarbiat Modarres for technical assistance during the analysis of the NMR.

\section{Conflict of Interest}

No conflict of interest associated with this work.

\section{Contribution of Authors}

The authors declare that this work was done by the authors named in this article and all liabilities pertaining to claims relating to the content of this article will be borne by them.

\section{Open Access}

This is an Open Access article that uses a funding model which does not charge readers or their institutions for access and distributed under the terms of the Creative Commons Attribution License (http://creativecommons.org/licenses/by 14.0) and the Budapest Open Access Initiative (http://www.budapestopenaccessinitiative.org/rea d), which permit unrestricted use, distribution, and reproduction in any medium, provided the original work is properly credited.

\section{REFERENCES}

1. Hedges AR. Industrial Applications of Cyclodextrins. Chem Rev 1998; 98: 2035-2044.

2. Hirayama F, Ukeama K. Cyclodextrin-based controlled drug release system. Adv Drug Deliv Rev 1999; 36: 125141.

3. De Sousa FB, Leite Denadai AM, Lula IS, Lopes JF, Dos Santos HF, De Almeida WB, Sinisterra $R D$. Supramolecular complex of fluoxetine with $\beta$ cyclodextrin: An experimental and theoretical study. Int $J$ Pharm 2008; 353: 160-169.

4. Carrier RL, Miller LA, Ahmed I. The utility of cyclodextrins for enhancing oral bioavailability. J Control Release 2007; 123: 78-99.

5. Bender ML, Komiyama M. Cyclodextrin Chemistry. NewYork: Springer-Verlag; 1978. 1 p.

6. Szejtli J. In: Cyclodextrin Technology. Kluwer, Dordrecht; 1998; $p 450$.

7. Ali SM, Asmat $F$, Maheshwari A, Koketsu M. Complexation of fluoxetine hydrochloride with $\beta$ cyclodextrin: A proton magnetic resonance study in aqueous solution. II Farmaco 2005; 60: 445-449.

8. Schneider HJ, Hacket $F$, Rudinger V, lkeda H. NMR studies of cyclodextrins and cyclodextrin complexes. Chem Rev 1998; 98: 1755-1786.

9. Guo W, Fung BM, Christian SD. NMR study of cyclodextrin inclusion of fluorocarbon surfactants in solution. Langmuir 1992; 8: 446-451.

10. Hwang FS, Hogen-Esch TE. Fluorocarbon-modified water-soluble cellulose derivatives. Macromolecules 1993; 26: 3156-3160.

11. Zhang HS, Hogen-Esch TE, Boschet F, Margaillan A. Complex formation of water-soluble polymers. Langmuir 1998; 14: 4972-4977.

12. Brown SE, Easton CJ, Lincoln SF. Complexation of fluorinated amino-acid derivatives by beta-cyclodextrin and gamma-cyclodextrin in aqueous solution- $F-19$ nuclear-magnetic-resonance study. Aust J Chem 1995; 48: 505-513.

13. Kitamura K, Kume M, Yamamoto M, Takegami S, Kitade T. 19F NMR spectroscopic study on the binding of triflupromazine to serum albumins. J Pharm Biomed Anal 2004; 36: 411-414.

14. Armspach D, Matt D. Metal-capped alpha-cyclodextrins: Squaring the circle. Inorg Chem 2001; 40: 3505-3509. 
15. Nicely VA, Dye JL. A general purpose curve fitting program for class and research use. J Chem Educ 1971; 48: 443-448.

16. David D, Ignacio VB, Jesus GM. Beta-cyclodextrin inclusion complexes with iodine: An advanced and inexpensive undergraduate chemistry experiment. J Chem Educ 1994; 71: 708-714.

17. HYPERCHEM, Release 502, Hypercube, Inc., Gainesville 1997.

18. Frisch MJ, Trucks GW, Schlegel HB, Scuseria GE, Robb MA, Cheeseman JR, Zakrzewski VG, Montgomery JA, Stratmann RE, Burant JC, et al. Gaussian Inc., Pittsburgh, PA 1998.

19. Connors $K A$. The stability of cyclodextrin complexes in solution. Chem Rev 1997; 97: 1325-1357.

20. Rekharsky MV, Inoue Y. Complexation thermodynamics of cyclodextrins. Chem Rev 1998; 98: 1875-1918.

21. Khan AR, Forgo P, Stine KJ, D'Souza VT. Methods for selective modifications of cyclodextrins. Chem Rev 1998; 98: 1977-1996.
22. Saenger W, Jacob J, Gessler K, Steiner T, Hoffmann D, Sanbe H, Koizumi K, Smith SM, Takaha T. Structures of the common cyclodextrins and their larger analoguesbeyond the doughnut. Chem Rev 1998; 98: 1787-1802.

23. Harata K. Structural aspects of stereodifferentiation in the solid state. Chem Rev 1998; 98: 1803-1827.

24. Aree T, Hoier H, Schulz B, Reck G, Saenger W. Novel type of thermostable channel clathrate hydrate formed by Heptakis (2,6-di-O-methyl)- $\beta$-cyclodextrin. 15 H2O- A Paradigm of the hydrophobic effect. Angew Chem Int Ed 2000; 39: 897-899.

25. Shamsipur M, Shafiee Dastjerdi L, Haghgoo S, Armspach $D$, Matt $D$, Aboul-Enein HY. Chiral selectors for enantioresolution and quantitation of the antidepressant drug fluoxetine in pharmaceutical formulations by $19 \mathrm{~F}$ NMR spectroscopic method. Anal Chim Acta 2007; 601: 130-138. 